\title{
Cancer-associated mutations in the canonical cleavage site do not influence CD99 shedding by the metalloprotease meprin $\beta$ but alter cell migration in vitro
}

\author{
Tillmann Bedau ${ }^{1}$, Neele Schumacher ${ }^{1}$, Florian Peters ${ }^{1}$, Johannes Prox ${ }^{1}$, Philipp \\ Arnold ${ }^{2}$, Tomas Koudelka ${ }^{3}$, Ole Helm ${ }^{4}$, Frederike Schmidt ${ }^{1}$, Björn Rabe ${ }^{1}$, Marlene \\ Jentzsch ${ }^{5}$, Philip Rosenstiel ${ }^{5}$, Susanne Sebens ${ }^{4}$, Andreas Tholey ${ }^{3}$, Stefan Rose- \\ John ${ }^{1}$ and Christoph Becker-Pauly ${ }^{1}$ \\ 1Unit for Degradomics of the Protease Web, Institute of Biochemistry, University of Kiel, 24118 Kiel, Germany \\ ${ }^{2}$ Anatomical Institute, University of Kiel, 24118 Kiel, Germany \\ ${ }^{3}$ Institute of Experimental Medicine, University of Kiel, 24118 Kiel, Germany \\ ${ }^{4}$ Institute for Experimental Tumor Research, University of Kiel, 24118 Kiel, Germany \\ ${ }^{5}$ Institute of Clinical Molecular Biology, University of Kiel, 24118 Kiel, Germany \\ Correspondence to: Christoph Becker-Pauly, email: cbeckerpauly@biochem.uni-kiel.de \\ Keywords: CD99, meprin $\beta$, proteolytic shedding, lung cancer, inflammation
}

Received: January 18, 2017 Accepted: June 17, $2017 \quad$ Published: July 04, 2017

Copyright: Bedau et al. This is an open-access article distributed under the terms of the Creative Commons Attribution License 3.0 (CC BY 3.0 ), which permits unrestricted use, distribution, and reproduction in any medium, provided the original author and source are credited.

\section{ABSTRACT}

Transendothelial cell migration (TEM) is crucial for inflammation and metastasis. The adhesion molecule CD99 was shown to be important for correct immune cell extravasation and is highly expressed on certain cancer cells. Recently, we demonstrated that ectodomain shedding of CD99 by the metalloprotease meprin $\beta$ promotes TEM in vitro.

In this study, we employed an acute inflammation model (air pouch/carrageenan) and found significantly less infiltrated cells in meprin $\beta$ knock-out animals validating the previously observed pro-inflammatory activity. To further analyze the impact of meprin $\beta$ on CD99 shedding with regard to cell adhesion and proliferation we characterized two lung cancer associated CD99 variants (D92H, D92Y), carrying point mutations at the main cleavage site. Interestingly, ectodomain shedding of these variants by meprin $\beta$ was still detectable. However the cleavage site shifted to adjacent positions. Nevertheless, expression of CD99 variants D92H and D92Y revealed partial misfolding and proteasomal degradation. A previously observed influence of CD99 on Src activation and increased proliferation could not be confirmed in this study, independent of wild-type CD99 or the variants D92H and D92Y. However, we identified meprin $\beta$ as a potent inducer of Src phosphorylation. Importantly, we found significantly increased cell migration when expressing the cancer-associated CD99 variant D92H compared to the wild-type protein.

\section{INTRODUCTION}

CD99 is a $32 \mathrm{kDa}$ highly O-glycosylated type I transmembrane protein, which is expressed on cells of the hematopoietic system and on endothelial cells $[1,2]$. The homophilic interaction of CD99 molecules on both immune and endothelial cell was identified as an essential step for transendothelial migration (TEM) of leukocytes from the blood vessel into surrounding tissue during inflammation $[1,3,4]$. Some studies showed that differential expression of CD99 is associated with several pathological conditions. For instance, high CD99 expression is a hallmark of Ewing sarcoma (EWS), a malignant mesenchymal bone tumor, and CD99 expression is routinely assessed as a prognostic marker [5, 6]. Conversely, loss of CD99 expression has been described in osteosarcoma, suggesting a tumor suppressor role of CD99 in this particular cellular context [7].

Recently, CD99 was found to be specifically cleaved by the metalloprotease meprin $\beta[8,9]$. Importantly, ectodomain shedding of CD99 by meprin $\beta$ and subsequent 
regulated intramembrane proteolysis by $\gamma$-secretase resulted in increased TEM of murine Lewis lung carcinoma (LLC) cells. The cleavage site in CD99 was identified within a highly conserved region, mainly consisting of negatively charged aspartate residues, which correlateswith the cleavage specificity of meprin $\beta$ [10].

Meprin $\beta$ is a zinc-dependent multidomain metalloprotease of the astacin family that acts as an ectodomain sheddase of type I transmembrane proteins at the plasma membrane but can also be shed itself by a disintegrin and metalloproteinase (ADAM) proteases [11]. The substrate repertoire of meprin $\beta$ includes other type I transmembrane proteins such as the amyloid precursor protein (APP) [12-14] as well as soluble extracellular proteins such as mucin 2 (MUC-2) [15] or procollagen I [16]. Under physiological conditions, meprin $\beta$ is expressed at the brush border membranes of the proximal kidney tubules and in the small intestine [11].

Interestingly, abnormal expression of CD99 and meprin $\beta$ have been implicated in human tumors. For instance, meprin $\beta$ mRNA levels are elevated in both primary and metastatic sites of pancreatic neuroendocrine tumors $[17,18]$. Meprin $\beta$ upregulation is thought to promote cancer cell migration and metastasis by cleaving extracellular matrix (ECM) proteins. In fact, meprin $\beta$ promotes TEM of murine carcinoma cells thereby potentially increasing their metastatic potential [9].

We hypothesized that CD99 cleavage by meprin $\beta$ plays a role in tumor development based on three reasons. Firstly, it is expressed on the endothelium and therefore might be involved in the extravasation of metastasizing tumor cells. Furthermore, it is upregulated in cancer suggesting that disruption of normal CD99 protein levels may be favorable for malignant transformation or tumor progression. And finally, meprin $\beta$ deficient mice exhibit an accumulation of CD99 protein in the lung suggesting a role of meprins in CD99 homeostasis [9]. Here, we report on two CD99 point mutations identified in primary human lung tumors that directly affect the meprin $\beta$ cleavage site. We speculated that the resulting amino acid exchanges may affect meprin $\beta$-mediated shedding and thereby alter functional properties such as cell proliferation and migration. Thus, we biochemically characterized the CD99 variants in cell based assays and furthermore, in a proof of principle approach, compared their influence on cell homeostasis and cell behavior to wild type (WT) CD99.

\section{RESULTS}

The CD99 adhesion molecule is an important regulator of immune cell extravasation (Figure 1A). We recently reported that CD99 ectodomain shedding by meprin $\beta$ promotes TEM [9]. This was shown in an in vitro assay using bEnd.3 endothelial cells and Lewis lung carcinoma (LLC) cells as migrating cells. To demonstrate the impact of meprin $\beta$ on cell migration in vivo, we now performed an acute inflammation model (air pouch), employing meprin $\beta$ knock-out mice $\left(M_{\text {ep }} 1 b^{--}\right)$and compared the number of transmigrated inflammatory cells to wild-type control animals. After generating a dorsal pouch in mice, carrageenan was injected to stimulate immune response (Figure 1B). Indeed, in the absence of meprin $\beta$ a significantly decreased number of infiltrated cells were observed in the pouch lavage compared to wild-type mice (Figure 1C, Supplementary Figure 1). This supports our previous in vitro findings and demonstrates that meprin $\beta$ contributes to TEM in vivo, a crucial step in inflammation and potentially also in cancer metastasis. We now aimed to further elucidate the importance of meprin $\beta$ mediated CD99 cleavage, as CD99 is one of the main cell adhesion molecules regulating cell extravasation [19].

Of note, both meprin $\beta$ cleavage sites identified in CD99 are located within amino acid sequence regions that are highly conserved across vertebrate species [9, 20, 21]. This suggests coevolution of protease and substrate and underlines the apparent functional relevance of these sequence motifs. The highly conserved regions (HCRs) II and III consist of the amino acid sequences $(\mathrm{F} / \mathrm{L})$ DLX(D/E)A(V/L) and (F/I)XDXDLXD, respectively (X: any amino acid), which renders them as ideal meprin $\beta$ cleavage sites considering the preference of the protease for negatively charged amino acid residues $(\mathrm{D} / \mathrm{E})$ around the scissile bond [10] (Figure 2A).

\section{Human lung cancer-associated point mutations in $C D 99$ gene cause amino acid exchanges directly within the meprin $\beta$ cleavage site}

In the BioMuta databank [22] two missense mutations in the CD99 gene are annotated that directly modify the meprin $\beta$ cleavage site. These variants are c. $274 \mathrm{G}>\mathrm{C}$ and c. $274 \mathrm{G}>\mathrm{T}$, which cause amino acid (AA) substitutions of Asp92 towards His92 (p.D92H) or Tyr92 (p.D92Y), respectively (Figure 2B). Both mutations were detected in primary tumor samples of two male patients suffering from lung squamous cell carcinoma (p.D92H) or lung adenocarcinoma (p.D92Y). Asp92, found at the $\mathrm{P} 1$ ' position, is the preferred cleavage site for meprin $\beta$ resulting in a $\mathrm{C}$-terminal fragment (CTF) II, which is further processed by $\gamma$-secretase [9] (Figure 2A). We hypothesized that loss of the negatively charged and preferred Asp92 would alter meprin $\beta$-mediated cleavage of CD99 and subsequent $\gamma$-secretase processing with possible impact on cancer cell biology.

\section{Peptides representing CD99 mutations are cleaved in vitro, however with a different cleavage site and kinetics}

In order to assess the ability of meprin $\beta$ to cleave the CD99 mutants in vitro, we initially analyzed synthetic peptides spanning the Asp92 cleavage site (Ser86-Glu103), 
containing either the WT or mutant (D92H and D92Y) AA sequence (Figure 2C). Indeed, all three peptides were cleaved by meprin $\beta$. Compared to the chromatogram of the full-length (FL) peptides alone, which eluted in one single peak, several peaks corresponding to cleaved peptides were detectable in the presence of recombinant meprin $\beta$ after RP-HPLC (Figure 2C). The elution fractions were collected and subjected to MALDI-TOF MS (Supplementary Figure 2) to identify newly derived $\mathrm{N}$-termini. Indeed, the preferred cleavage site at position Asp92 (WT, big arrowhead) was barely used anymore in case of the mutants with His or Tyr at this particular position. Instead, the main cleavage site shifted to Asp94, two AA further C-terminal (Figure 2C, big arrowheads). Also, both mutants were cleaved at other AA, thereby generating additional minor cleavage products (Figure 2C, small arrowheads). Furthermore, we determined cleavage kinetics by incubating the peptides with meprin $\beta$ for 15 , 30, 60, and 120 minutes (Supplementary Figure 3). By calculating the integral of the decreasing FL peak and the increasing main cleavage product peak, we quantified the cleavage process over time (Figure 2D and 2E, respectively). Interestingly, substitution of only Asp92 markedly changed the cleavage kinetics for the $\mathrm{D} 92 \mathrm{H}$ mutant. The D92H peptide was processed much slower than the WT peptide. After $15 \mathrm{~min}$, the FL peak area still amounted to $40 \%$ of the initial area while for the WT peptide the area was already reduced to $24 \%$ (Figure 2D). The difference was even more pronounced after $30 \mathrm{~min}$ : $33 \%$ compared to $8 \%$. These data are in line with a slower

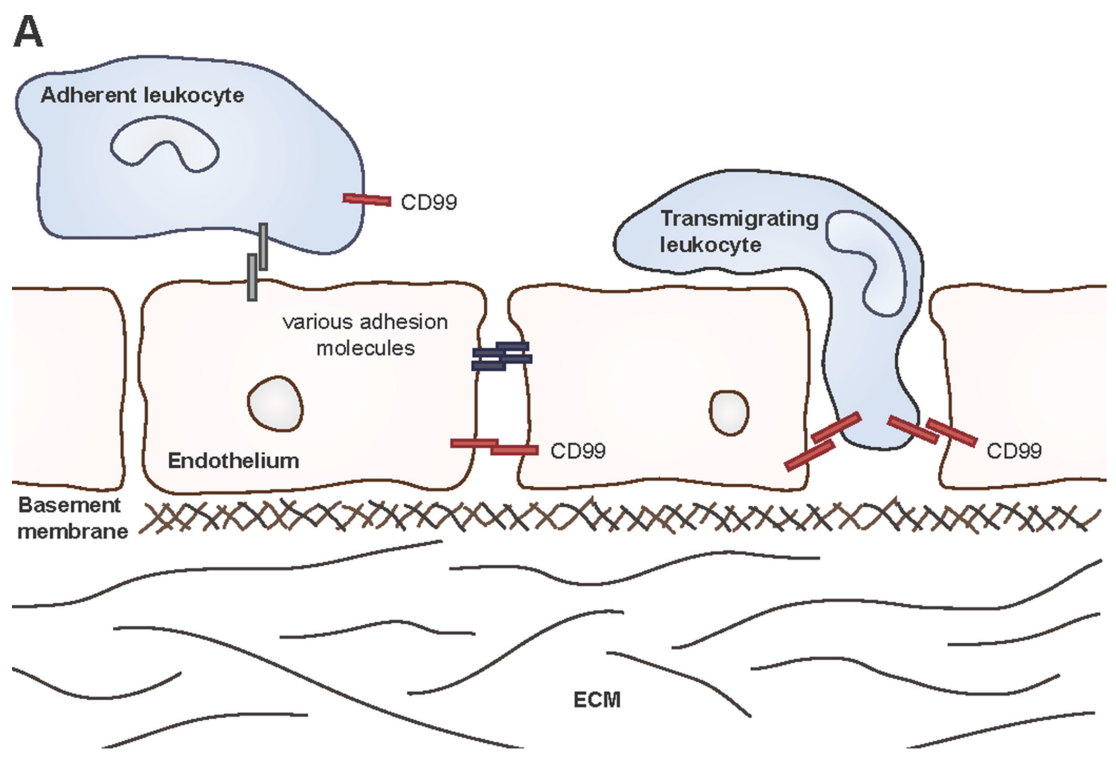

B

Air pouch model
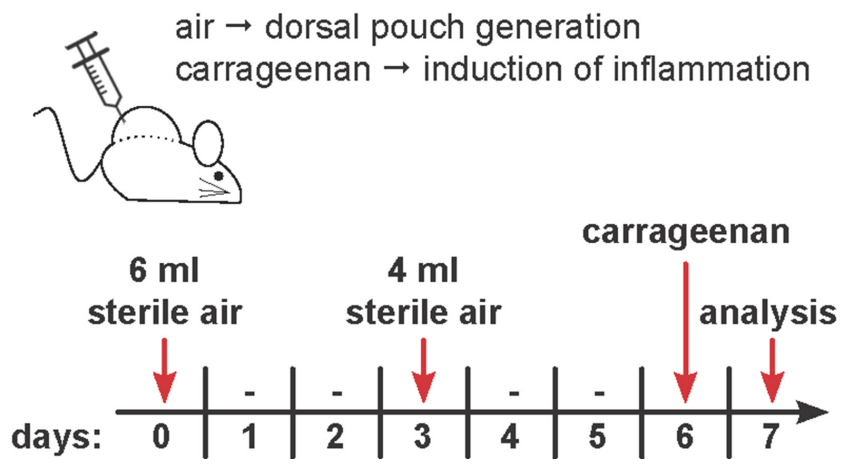

C

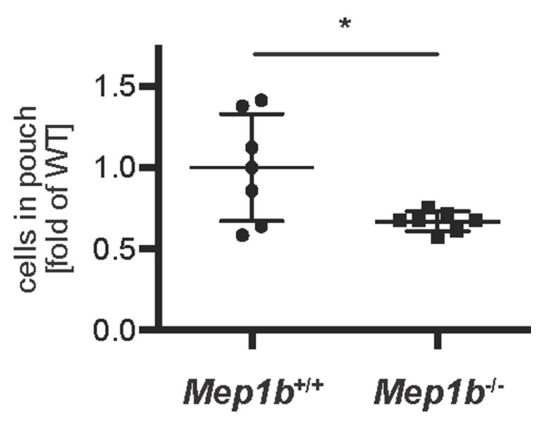

Figure 1: Meprin $\boldsymbol{\beta}$ is important for immune cell extravasation during acute inflammation. (A) CD99 is crucial for TEM. Extravasation of leukocytes through endothelial layers requires specific interactions of adhesion molecules between both cell types. Chemokines and other biologically active factors secreted by mesenchymal cells induce leukocyte migration. Whether or not CD99 also plays a role in tumor cell extravasation during metastasis is unknown because these mechanisms are much more heterogeneous. (B) For an acute inflammation model, $\mathrm{Mep}^{b^{+/+}}$and $\mathrm{Mep} \mathrm{b}^{-/-}$mice were injected subcutaneously with sterile air. Six days later carrageenan was administered into the dorsal air pouch to induce an immune cell infiltration. After $24 \mathrm{~h}$, the pouch was washed and the lavage fluid collected for further analysis. (C) Cells in the pouch lavage fluid were counted. Mep $1 b^{-/-}$mice had significantly less infiltrated cells than $M e p 1 b^{+/+}$mice. 
increase of the cleavage product peak area (Figure 2E). For the D92Y peptide, however, the cleavage kinetics were similar to the WT peptide.

\section{CD99 mutants show different posttranslational modifications, but are equally processed by meprin $\beta$ at the cell surface}

To study the CD99 mutants in cellulo, we generated C-terminally myc-/FLAG-tagged expression constructs, transfected HeLa cells, and analyzed cell lysates by Western blot (Figure 3A). CD99 WT appeared as two distinct bands: an intense upper one at around $35 \mathrm{kDa}$ proposed to correspond to the fully glycosylated, properly folded, membrane-bound protein; and a weaker band at around $30 \mathrm{kDa}$ corresponding to a non-or partially-glycosylated (immature) form. In contrast, expression of the D92H and D92Y variants revealed additional bands below $30 \mathrm{kDa}$ and a shift of the full-length protein towards the $30 \mathrm{kDa}$ form was observed. Co-expression of all CD99 variants with meprin $\beta$ resulted in the generation of CTFs of similar size. Of note, a diffuse smear over a broad molecular weight range was observed in Western blots when the two CD99 mutants and meprin $\beta$ were co-expressed. This indicates that more cleavage sites are used and more degradation is taking place, which correlates with the additional cleavage sites identified in vitro (Figure 2C). Addition of the $\gamma$-secretase inhibitor DAPT led to accumulation of CTF II in all cases (Figure 3A) as previously observed for WT CD99 [9]. To validate the cleavage sites identified in vitro in a cellular context, we excised immune-precipitated CD99 CTFs II from a Coomassie-stained SDS gel and performed LC-ESI MS/MS (Supplementary Figure 4). Indeed, we could confirm that, in case of the mutants, the cleavage site used by meprin $\beta$ to generate CTF II shifts from Asp92 to Asp94 as observed in the peptide assays (Figure 2C). To analyze the ability of soluble shed meprin $\beta$ to cleave the CD99 mutants, we applied recombinant meprin $\beta$ (the soluble ectodomain containing the active protease domain) time-dependently to CD99-overexpressing $\mathrm{HeLa}$ cells and monitored the CD99 expression on the cell surface by flow cytometry (Figure 3B). Quantification shows that after 1 hour almost all CD99 was shed from the cells (Figure 3C). Remarkably, contrary to the in vitro kinetics (Figure 2D), there was no obvious difference in shedding kinetics between CD99 WT and the two mutants in cellulo (Figure 3C).

\section{CD99 mutants are constitutively shed by endogenous meprin $\beta$ in COLO 320 cells}

We used a human colorectal adenocarcinoma cell line (COLO 320) with high endogenous expression of meprin $\beta$ to rule out the possibility that differences in CD99 cleavage were merely an artifact of meprin $\beta$ overexpression. We therefore transfected COLO 320 cells with the different
CD99 constructs and analyzed cell lysates by Western blot, which confirmed a similar cleavage pattern compared to HeLa cells (Figure 3D). Indeed, application of the meprin $\beta$ inhibitor actinonin [23] resulted in accumulation of CD99 full-length protein indicating decreased ectodomain shedding of the adhesion molecule (Figure 3D). This was further confirmed by flow cytometry where an accumulation of CD99 protein was observed at the cell surface after treatment with actinonin (Figure 3E, 3F).

We further investigated the subcellular localization of meprin $\beta$ and the two CD99 variants by confocal laser scanning microscopy and could demonstrate colocalization at the cell surface (Figure 4A). Of note, expression of $\mathrm{D} 92 \mathrm{H}$ and $\mathrm{D} 92 \mathrm{Y}$ showed a stronger intracellular signal compared to CD99 WT. To analyze whether the actual proteolytic cleavage event also takes place at the cell surface, we additionally performed a biotinylation assay of surface proteins and analyzed these samples by Western blot. As already published for CD99 WT [9], not only the full-length CD99 protein but also CTF II could be detected in the biotinylated and pulled-down fraction in case of both mutants (Figure 4B), thus demonstrating that cleavage must take place at the cell surface. Interestingly, all proteins corresponding to the lower-migrating full-length bands between 22 and $30 \mathrm{kDa}$ usually present in lysate fractions upon CD99 single transfection, were not precipitated by streptavidin. Therefore, the immaturity of these proteins (misfolding or incomplete glycosylation) most likely accounts for their lower molecular weight and intracellular accumulation. It is also noteworthy that the intensity of the full-length band at $35 \mathrm{kDa}$ is completely restored or even higher than CD99 WT levels for both mutants when compared to the non-precipitated lysate control.

\section{Proteasomal inhibition leads to intracellular accumulation of D92H CTFs}

In order to examine whether the different immature forms and the CTFs originating from cleavage of the CD99 variants cause cellular stress and initiate proteasomal activity we added the proteasome inhibitor MG132 to transfected HeLa cells and subsequently analyzed cell lysates by Western blot. There was only minor accumulation of CD99 CTFs when the WT construct was expressed together with meprin $\beta$ (Figure 5A). However, upon co-transfection of D92H with meprin $\beta$, significant accumulation of two CTFs migrating slightly higher than CTF II was detected. This again indicates that this mutant is prone to more unspecific cleavage, thus generating CTFs, which are potentially detrimental for the cell and thus should be discarded.

\section{CD99 mutants do not induce ER stress}

A quality control mechanism termed unfolded protein response (UPR), or ER stress, can sense misfolded proteins within the ER, which leads to a halt of translation, 


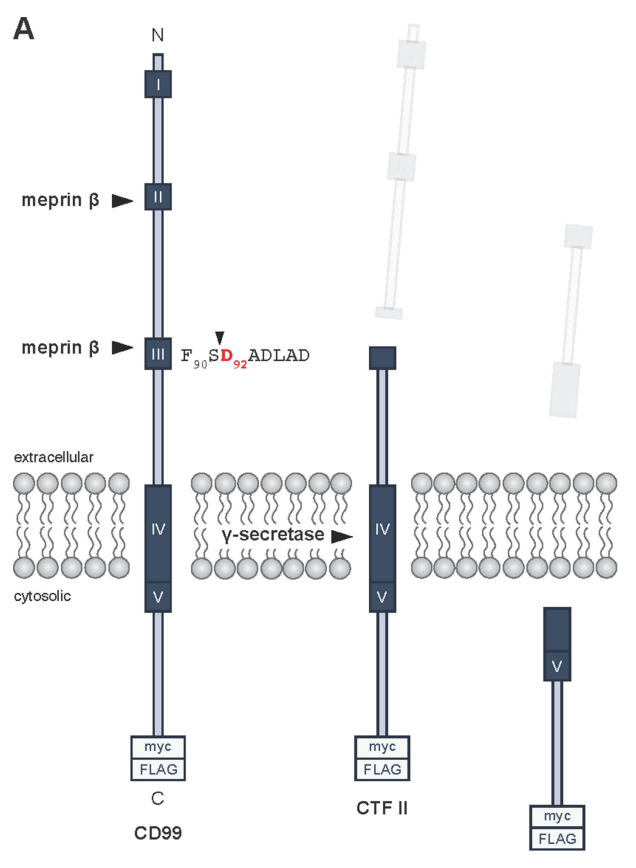

ICD

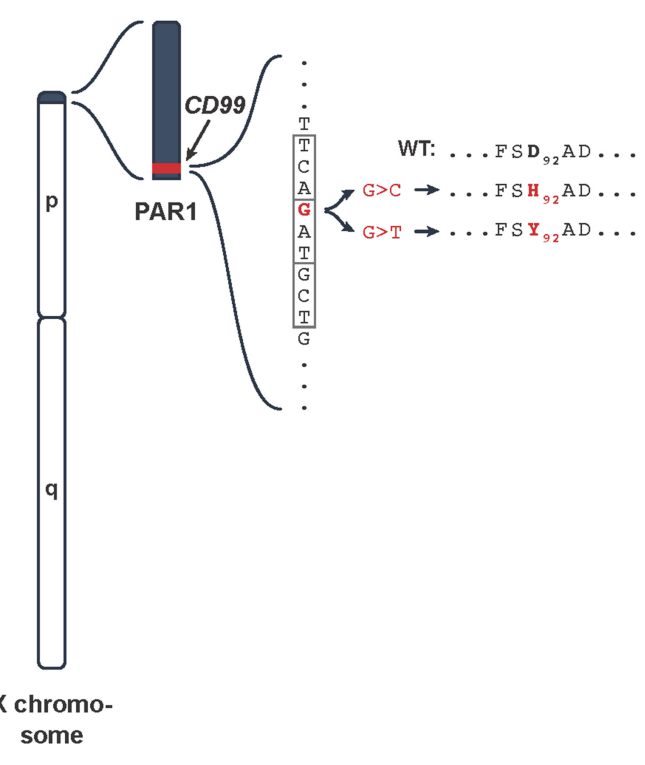

C
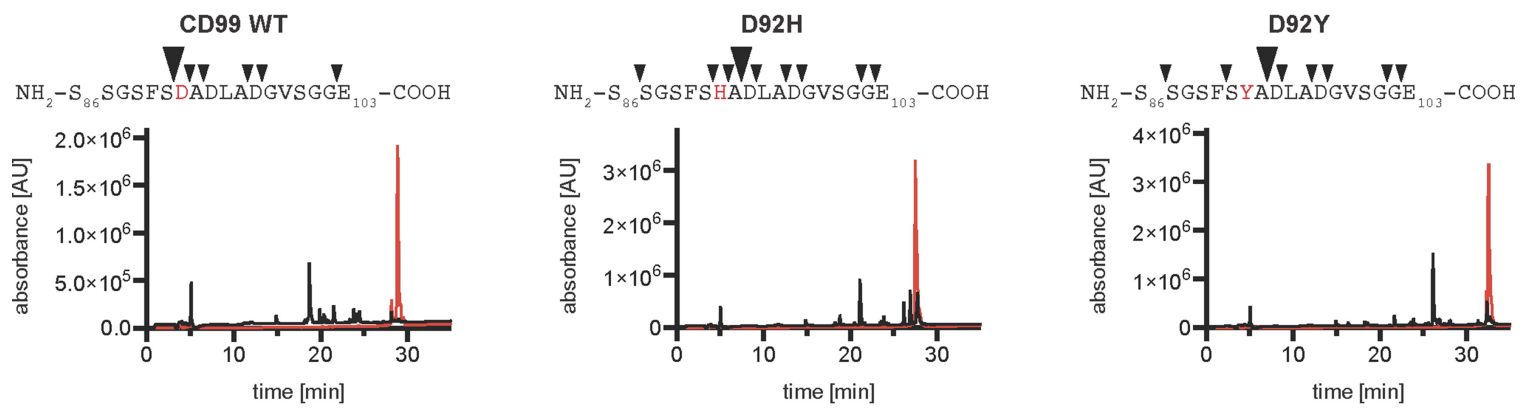

D

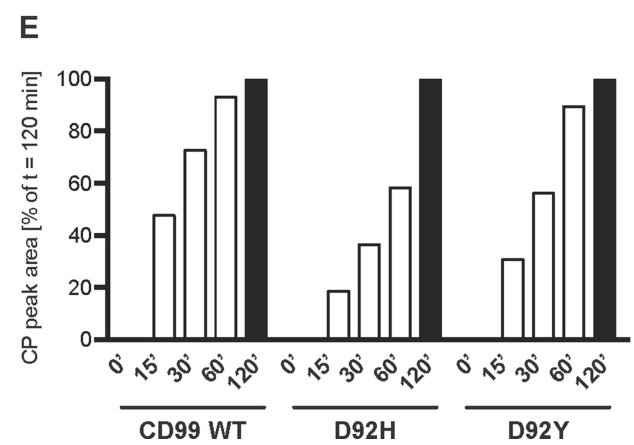

Figure 2: $C D 99$ lung cancer-associated mutations of Asp92 lead to a shift of the meprin $\beta$ cleavage site. (A) Schematic diagram of CD99 processing at the cell surface. Meprin $\beta$ cleaves the full-length CD99 protein within highly conserved regions (HCR) II and III creating C-terminal fragments (CTF) I and II, respectively. CTF II is further processed by $\gamma$-secretase thereby releasing an intracellular domain (ICD) into the cytosol. For all further experiments, a C-terminally myc-/FLAG-tagged construct was used. HCRs are indicated by dark blue boxes with white Roman numerals. Arrowhead indicates meprin $\beta$ cleavage site between Ser91 and Asp92 (red) affected by the mutations. C, C-terminus. N, N-terminus. (B) Genomic location of the lung cancer-associated CD99 patient mutations. The human $C D 99$ gene (red) is located in the pseudoautosomal region (PAR) 1 at the end of the short arm of the $\mathrm{X}$ chromosome (blue). The mutations c.274G $>$ C and c.274G $>\mathrm{T}$ (situated in exon 6) cause amino acid exchanges from Asp92 to His92 and Tyr92, respectively, thereby leading to loss of negative charge at the P1' position, which is preferred by meprin $\beta$. p, p arm. q, q arm. (C) RP-HPLC chromatogram of synthetic peptides representing CD99 WT, D92H, and D92Y. Peptides spanning the meprin $\beta$ cleavage site around Asp92 were analyzed alone (red graph) or after incubation with $15 \mathrm{nM}$ recombinant meprin $\beta$ for $1 \mathrm{~h}$ (black graph). Collected elution fractions were analyzed by MALDI-TOF MS and several cleavage sites were identified within the peptide sequences (black arrowheads). AU, arbitrary units. (D) Quantification of the decreasing FL peak areas from (Supplementary Figure 3). (E) Quantification of the increasing cleavage product peak areas from (Supplementary Figure 3). 
A

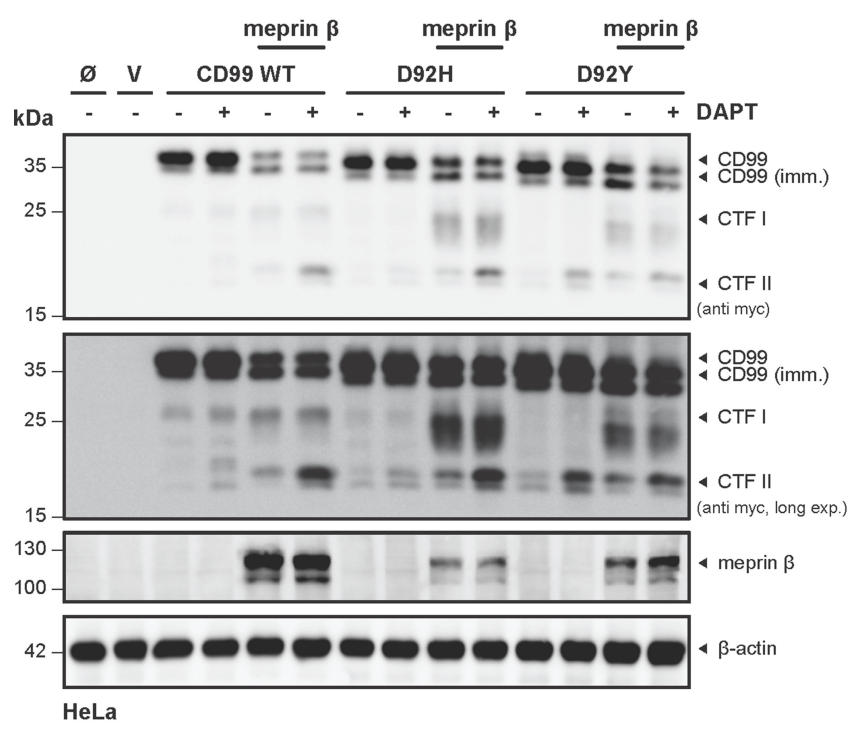

C

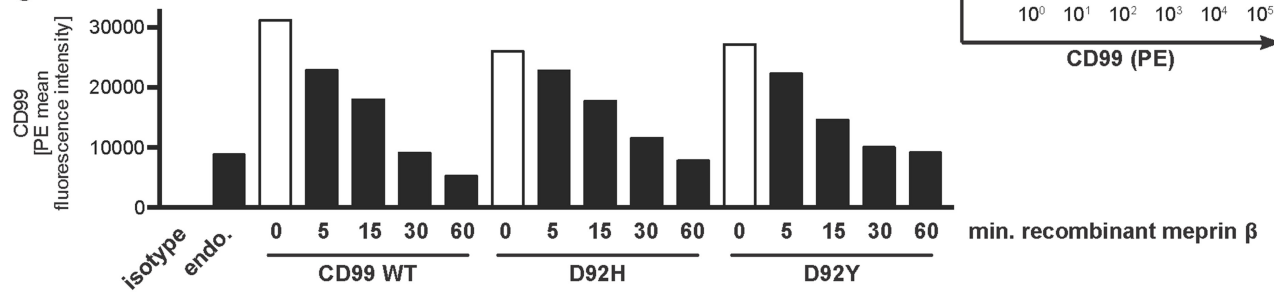

D

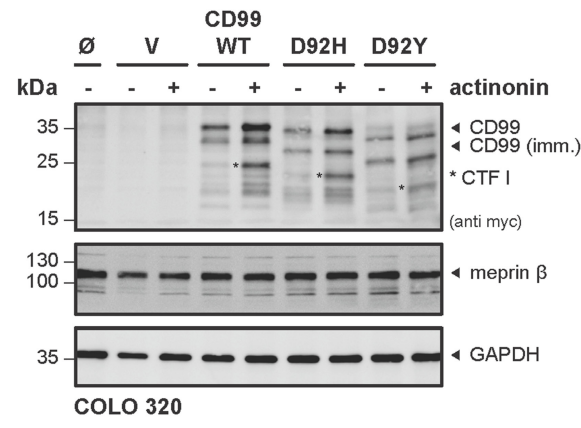

$\mathbf{F}$

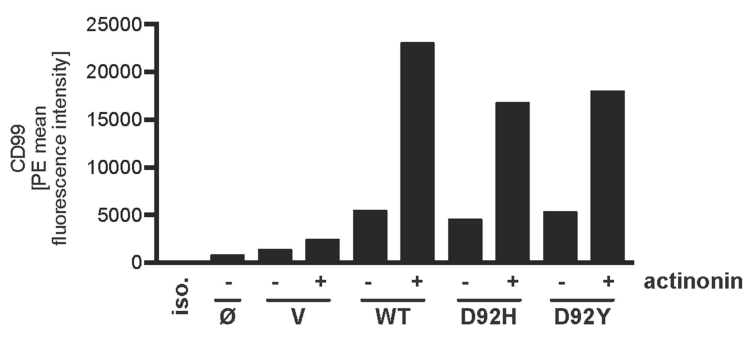

B
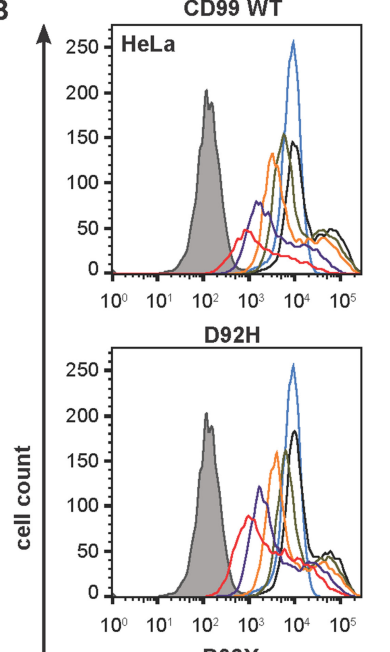

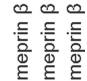

这

言 言

능ㅇㅇ

\&.

용요용

| | |
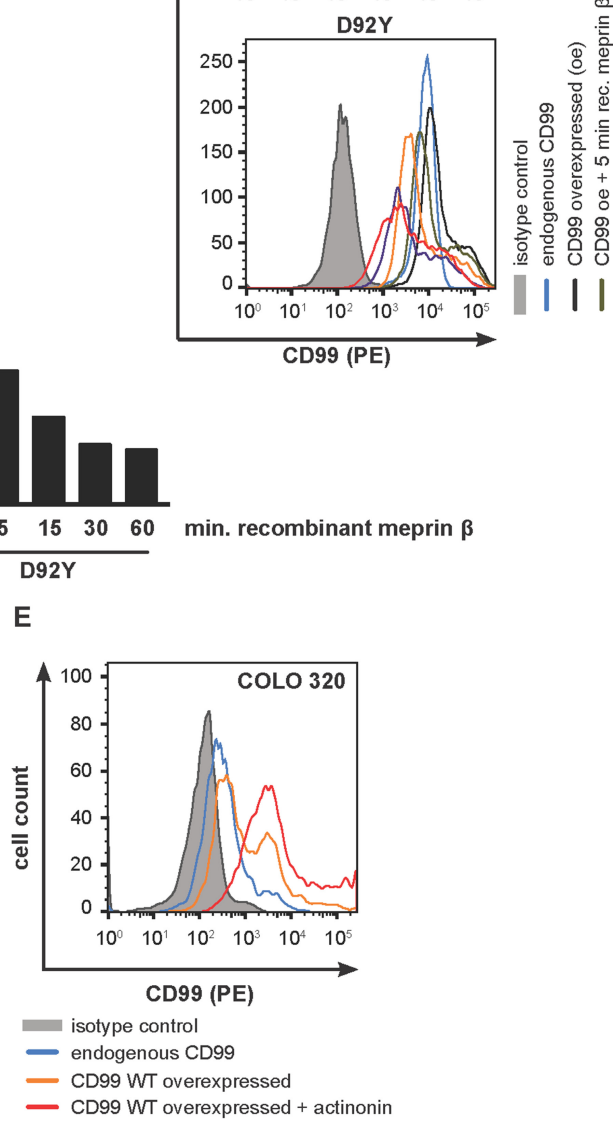

Figure 3: Meprin $\beta$-mediated shedding of CD99 variants induce regulated intramembrane proteolysis by $\gamma$-secretase. (A) HeLa cells were transfected with CD99 WT, D92H or D92Y, with or without meprin $\beta$. Cell lysates were analyzed by Western blot using a specific meprin $\beta$ or anti-myc antibody. $\beta$-actin served as loading control. For accumulation of $\gamma$-secretase dependent cleavage products the specific inhibitor DAPT $(0.6 \mu \mathrm{M}, 18 \mathrm{~h}$ prior to cell lysis) was applied. (B) To investigate cellular localization of CD99 and meprin $\beta$ interaction we applied recombinant active meprin $\beta(25 \mathrm{nM})$ to CD99-overexpressing HeLa cells and analyzed surface localization by flow cytometry. Here, a time-dependent decrease of the signal for CD99 WT and the cancer associated variants at the plasma membrane 
was observed. Signal specificity was verified by analysing CD99 overexpressing HeLa cells with IgG2a PE isotype control antibody. (C) Quantification of (B) using mean values of PE signal. Data represent PE mean values of one of three independent experiments. (D) COLO 320 cells, constitutively expressing high levels of endogenous meprin $\beta$, were transfected with CD99 WT, D92H or D92Y and treated with the meprin $\beta$ inhibitor actinonin. GAPDH served as a loading control. Asterisks indicate CTF I fragments. (E) To analyze inhibition of endogenous meprin $\beta$ with regard to CD99 shedding, COLO 320 cells were transfected with all CD99 variants and surface localization was measured by flow cytometry. (F) Quantification of (E) using mean values of PE signal. Data represent PE mean values of one of three independent experiments.

supports folding by upreglation of chaperones, but also enables degradation of excessive misfolded proteins. Ultimately, if the state is not resolved, the UPR may also lead to induction of programmed cell death. Based on the altered Western blot pattern of the CD99 variants, we hypothesized that these proteins might not be properly folded during synthesis and thus may trigger the UPR machinery. To address this, we analyzed cell lysates and total mRNA from HeLa cells for potential effects of the mutations in the presence or absence of meprin $\beta$. As readout for UPR induction, we used several molecular markers (Grp78, p-eIF2 $\alpha$, Grp94, XPB1 splicing) that have been shown to be sensitive for ER stress (Figure 5B). As a positive control, tunicamycin was used, which is known to induce ER stress via inhibition of proper glycosylation. Indeed, in the tunicamycin-treated sample induction of Grp78 and XBP1 splicing was evident. However, we could not detect significant alterations of these markers in the cells transfected with CD99 D92H and D92Y, indicating that the mutants do not induce ER stress.

\section{Meprin $\beta$ induces Src phosphorylation independent of CD99}

It was reported that CD99 attenuates Src kinase activity thereby increasing tumor malignancy and metastasis [24]. To investigate this in terms of proteolysis, we analyzed the impact of CD99 cleavage by meprin $\beta$ with regard to Src phosphorylation.

Therefore, HeLa cells were transfected with CD99

WT in the presence or absence of recombinant meprin $\beta$ and $p$-Src was analyzed by Western blot (Figure 6A). Surprisingly, no obvious change in p-Src was detected when CD99 alone was expressed. However, incubation with active meprin $\beta$ resulted in strong increase of $\mathrm{p}-\mathrm{Src}$, but not p-PKA, which is also thought to be involved in CD99 signaling [25]. In order to compare our experiments with the previously published data [24], we additionally transfected U2-OS (osteosarcoma) cells with CD99 WT or the cancer associated variants D92H and D92Y. However, application of meprin $\beta$ resulted in enhanced p-Src, independent of CD99 (Figure 6B). Since we could not observe the published effect on p-Src, we considered that overexpression of CD99 might to some extent interfere with Src activation. Hence, we performed a knock-down of endogenous CD99 by siRNA. The specific siRNA-mediated decrease in CD99 cell surface expression was efficient $(\sim 55 \%)$ as analyzed by flow cytometry (Figure 6C, 6D). Remarkably, incubation of
U2-OS cells with $25 \mathrm{nM}$ meprin $\beta$ resulted in almost complete loss of CD99 at the plasma membrane and could partially be rescued through application of the meprin $\beta$ inhibitor actinonin (Figure 6D). However, knock-down of CD99 in U2-OS cells did not result in changed p-Src levels (Figure 6E, 6F), confirming the data from CD99 overexpression. Again, application of recombinant meprin $\beta$ strongly increased $\mathrm{p}-\mathrm{Src}$ (Figure 6E, 6F).

\section{CD99 variant D92H causes increased cell migration}

After showing that both CD99 variants can be shed by meprin $\beta$ and that they have no influence on Src activation, we investigated their effect on cell proliferation and migration where changes are typically associated with cancer and metastasis. Transiently transfected HeLa cells were seeded into transwell chambers and allowed to migrate through a porous membrane for 24 hours. Migration was monitored in real time using the xCELLigence system and increases in electrical impedance are reflected in an arbitrary unit, the cell index (CI) (Figure 7A). CI values at $12 \mathrm{~h}$ and $24 \mathrm{~h}$ were used for quantification and show significantly increased migration of cells overexpressing the D92H variant compared to cells overexpressing the CD99 WT protein. Migration of D92Y-overexpressing cells was not altered (Figure 7B). Proliferation was analyzed using an MTT assay. Here, no significant difference in proliferation rate was observed for the CD99 variants compared to cells transfected with CD99 WT (Figure 7C).

\section{DISCUSSION}

Upregulation of the metalloprotease meprin $\beta$ and its substrate CD99 is associated with several types of human cancers suggesting functions in tumor development. A common step in inflammation and metastasis is cell extravasation through endothelial cell layers $[19,26]$. We recently demonstrated that CD99 is a substrate of meprin $\beta$ in vivo and that this cleavage event promotes TEM in vitro [9]. In this study, we confirmed the pro-inflammatory activity of meprin $\beta$ in an acute inflammation model, where we observed significantly decreased numbers of infiltrated cells in meprin $\beta$ knock-out mice compared to WT animals. Hence, we hypothesized that the proteolytic interaction of meprin $\beta$ and CD99 is important for TEM in health and disease, and therefore investigated two CD99 point mutations, which were identified in two primary human lung tumors [22]. Since the mutations D92H and 
A
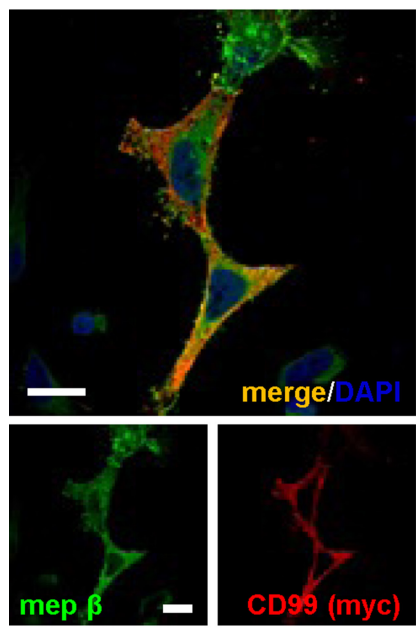

HeLa
$\mathrm{D} 92 \mathrm{H}$
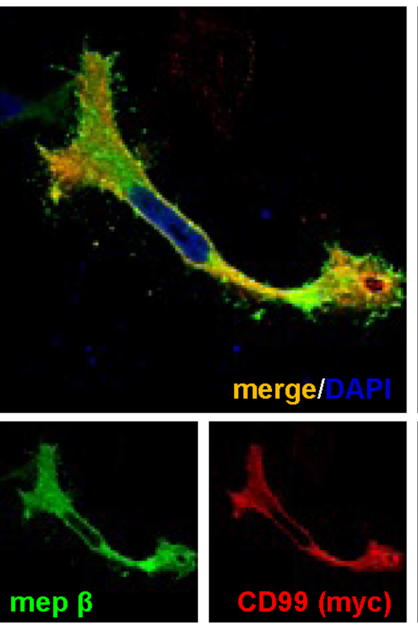
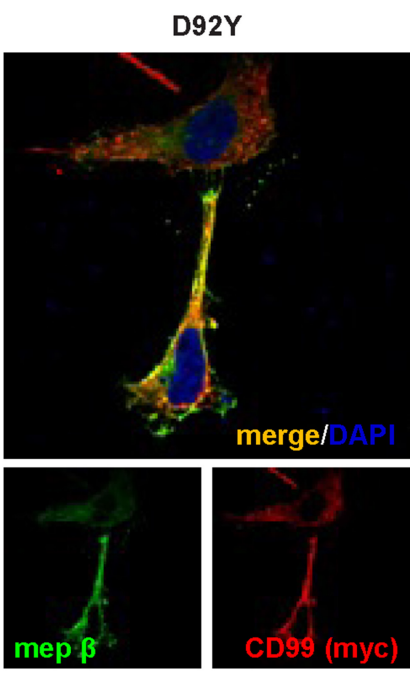

B
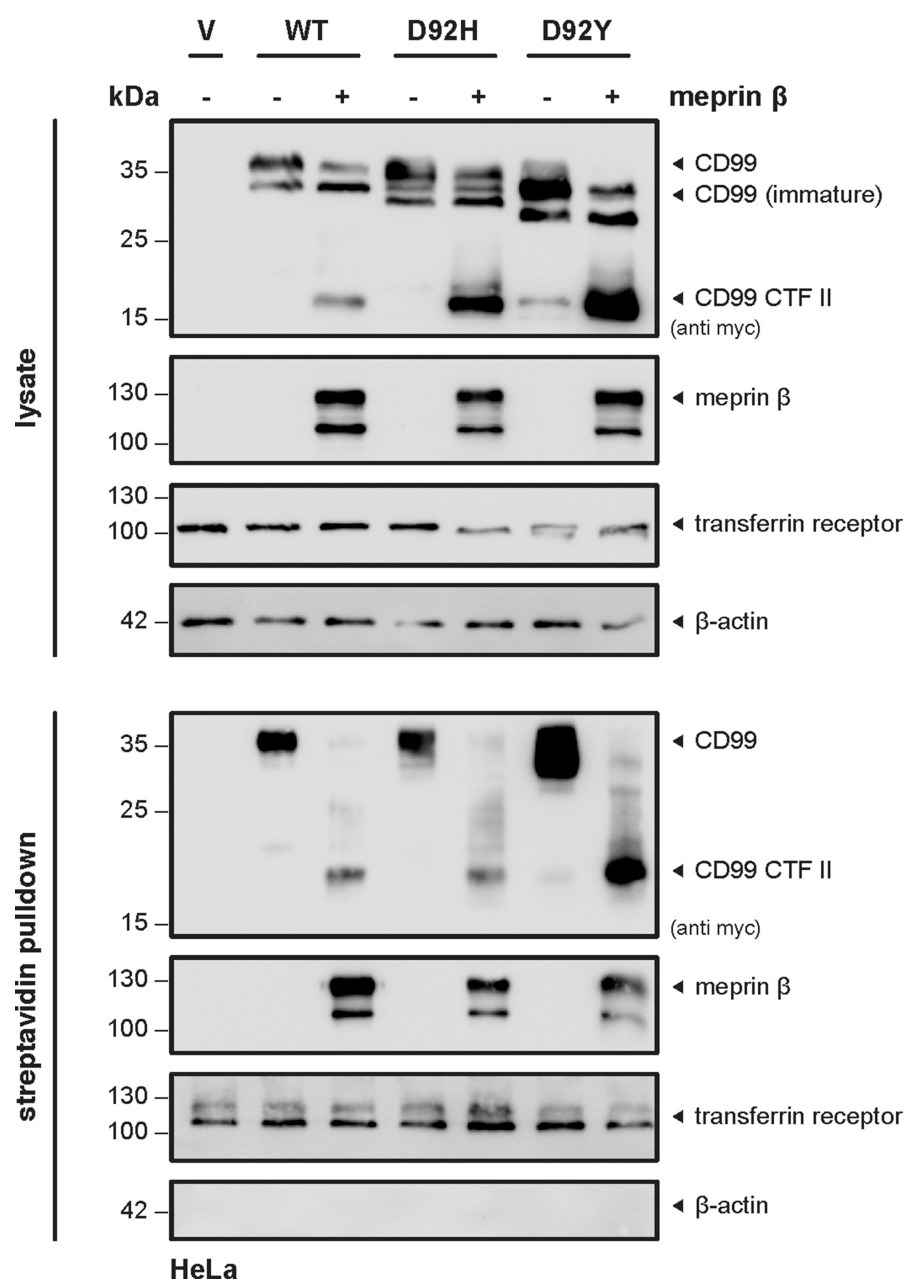

Figure 4: Only full-length mature CD99 variants are present at the cell surface. (A) HeLa cells transfected with CD99 WT, $\mathrm{D} 92 \mathrm{H}$ or D92Y and meprin $\beta$ showed co-staining of protease and substrate at the cell surface using confocal fluorescence microscopy. Of note, more intracellular staining was observed for the cancer-associated variants compared to CD99 WT. Bar $=20 \mu \mathrm{m}$. (B) Cell surface proteins of HeLa cells transfected with CD99 WT, D92H or D92Y and meprin $\beta$ were labelled by primary amine biotinylation, pulled down using streptavidin sepharose beads, and analyzed by Western blot. When coexpressed with meprin $\beta$, CTF II fragments appeared for all CD99 variants. For accumulation of $\gamma$-secretase dependent cleavage products the specific inhibitor DAPT $(0.6 \mu \mathrm{M}, 18 \mathrm{~h}$ prior to cell lysis $)$ was applied. Transferrin receptor served as control for correct biotinylation. 

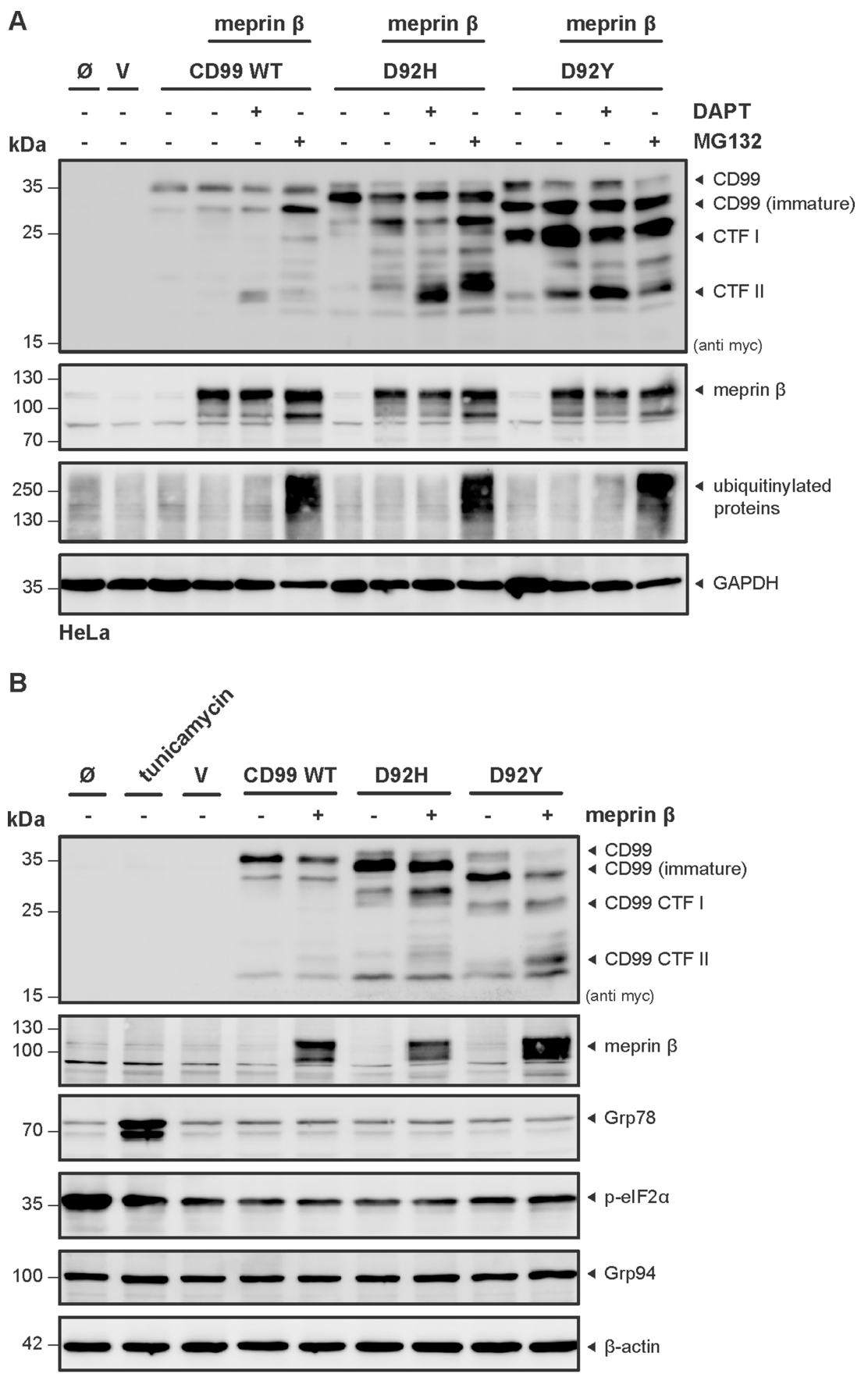

HeLa: lysate

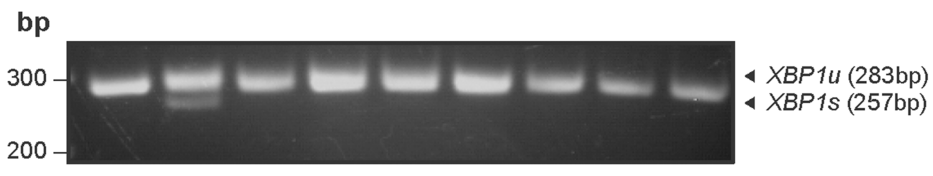

HeLa: total mRNA RT-PCR

Figure 5: Misfolding and proteasomal degradation of Cd99 WT, D92H and D92Y does not induce ER-stress. (A) HeLa cells were transfected with CD99 WT, D92H or D92Y, with or without meprin $\beta$. DAPT was used to inhibit $\gamma$-secretase activity and MG132 to prevent proteasomal degradation. Cell lysates were analyzed by Western blot using a specific meprin $\beta$ or anti-myc antibody. Efficacy of MG132 treatment was validated by visualizing accumulation of ubiquitinylated proteins. GAPDH served as a loading control. (B) HeLa cells were transfected with CD99 WT, D92H or D92Y, with or without meprin $\beta$ and cell lysates were analyzed by Western blot using antimyc and specific meprin $\beta$ antibodies. Additionally, ER stress-sensitive proteins were analyzed. mRNA of the same cells was isolated and analyzed for $X B P 1$ splicing by RT-PCR. In both cases tunicamycin, an inductor of ER stress, was used as positive control. $X B P 1 u$, unspliced $X B P 1 ; X B P 1 s$, spliced $X B P 1$. 
A

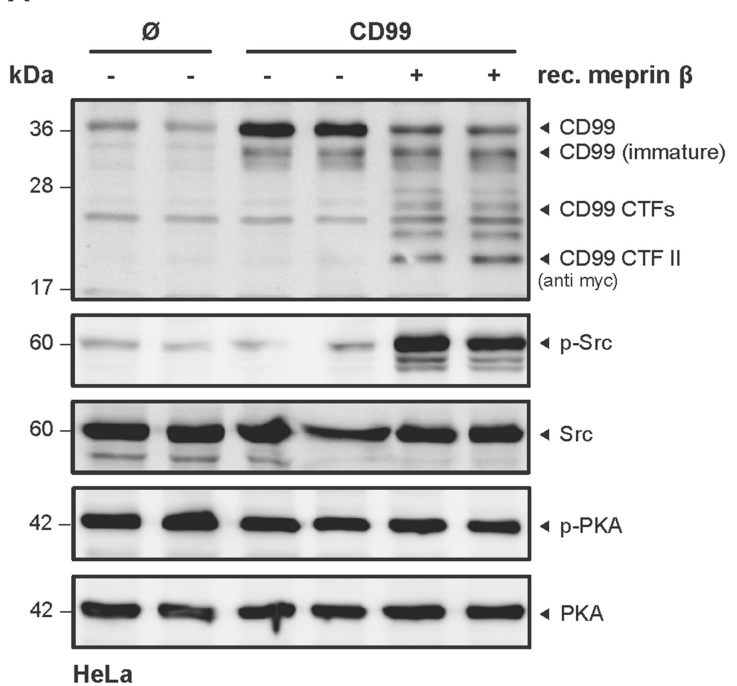

B

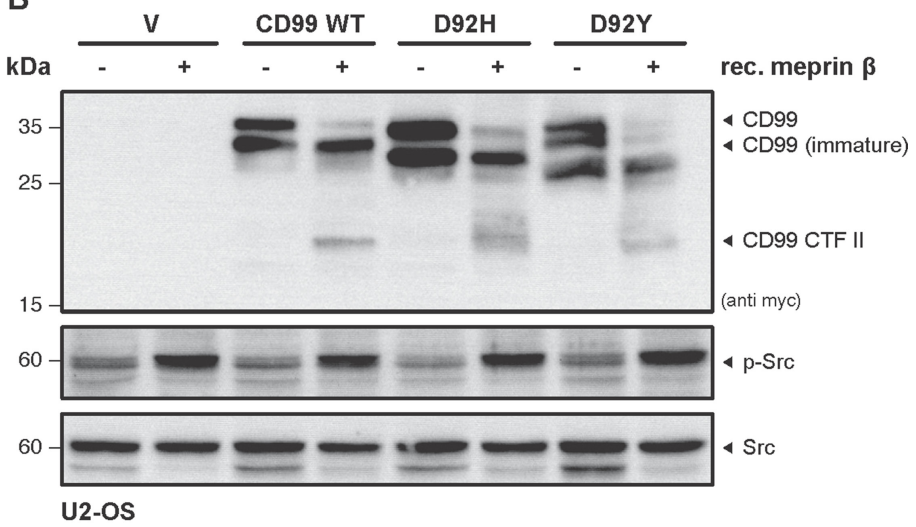

C

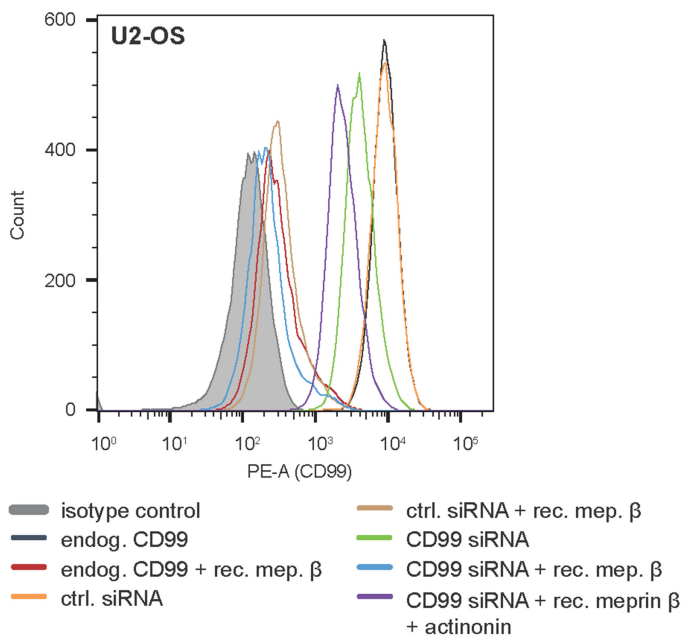

E

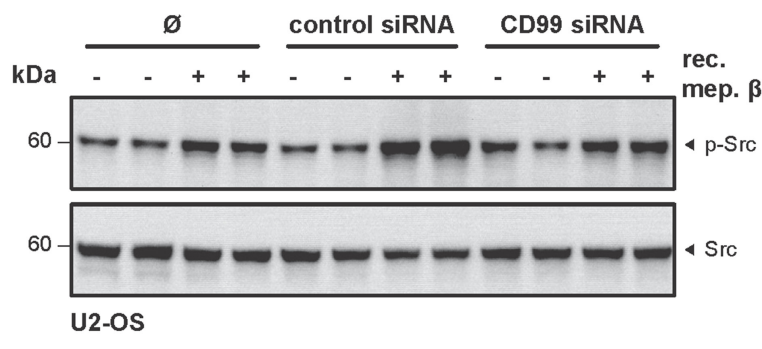

D

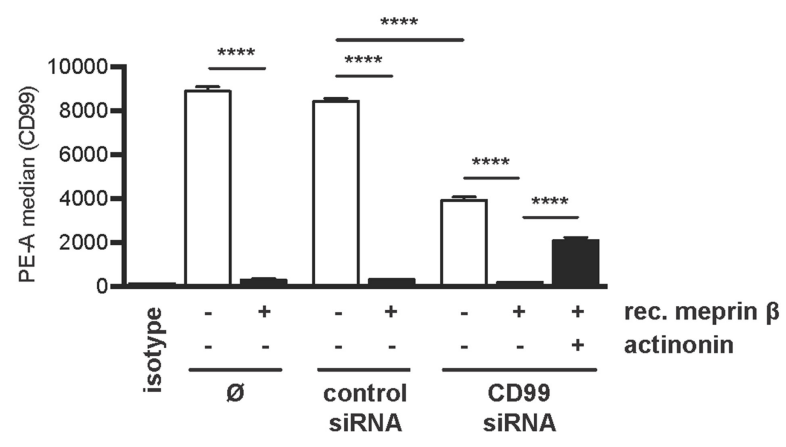

$\mathbf{F}$

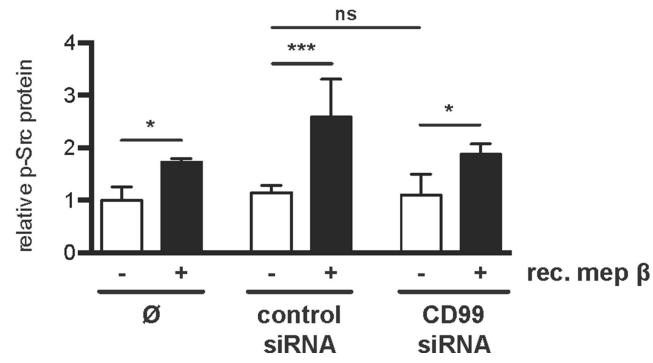

Figure 6: Meprin $\boldsymbol{\beta}$ induces Src phosphorylation independent of CD99. (A) HeLa cells were transfected with CD99, incubated with recombinant meprin $\beta(25 \mathrm{nM})$ for $1 \mathrm{~h}$, and lysates were analyzed for p-Src and p-PKA by Western blot. (B) To further test if Src activation is CD99-dependent, U2-OS were transfected with CD99 WT, D92H or D92Y in the presence or absence of meprin $\beta$ (25 nM, $1 \mathrm{~h}$ ) and analyzed by Western blot. (C) siRNA-mediated knockdown of endogenous CD99 in U2-OS cells was validated by flow cytometry. Knockdown specificity was validated by non-targeting siRNA. Incubation with recombinant meprin $\beta$ ( $25 \mathrm{nM}, 1 \mathrm{~h})$ revealed shedding of CD99. Flow cytometry signal specificity was validated by using isotype control. (D) Quantification from (C) of cell surface CD99 in U2-OS cells by flow cytometry after siRNA transfection and application of recombinant meprin $\beta$. Almost complete loss of CD99 was observed after meprin $\beta$ incubation, which could partially be rescued by adding the inhibitor actinonin $(10 \mu \mathrm{M}, 1 \mathrm{~h})$. About $50 \%$ knockdown efficiency of CD99 was achieved by transfection with specific siRNA. Data represent mean of PE median values \pm SD of technical duplicates from (C) and represent one of three individual experiments. ANOVA; ****p $<0.0001$. (E) Cell lysates were produced from samples in $(\mathrm{C})$ and then analyzed by Western blot. Only meprin $\beta$ treated cells showed increased p-Src, whereas CD99 knockdown had no obvious effect. (F) Quantitative analysis of p-Src signal intensity in relation to Src from (E) calculated by Image J (version 1.49). Data represent mean $\mathrm{p}-\mathrm{Src} / \mathrm{Src}$ ratio $\pm \mathrm{SD}$ of two individual experiments with technical duplicates as shown in (E). ANOVA; ***p $<0.001 ; * P<0.05$. 
D92Y cause an exchange of the preferred Asp92 to a disfavored amino acid within the meprin $\beta$ cleavage site, we investigated whether shedding and cancer-associated cell behavior such as proliferation and migration would be altered and may contribute to tumor development and metastasis. Our results show that the CD99 variants D92H and D92Y are still shed by meprin $\beta$, albeit with the cleavage site shifted to the adjacent $\mathrm{C}$-terminal aspartate residues within the HCR III ((F/I)XD ${ }_{92}$ XDLXD) of CD99. Nevertheless, cleavage kinetics for D92H were slower when compared to the other CD99 variants. Interestingly, both cancer associated mutations showed a different band pattern in Western blot analysis. The additional, slightly lowermigrating bands, could not be detected at the cell surface, but were partially sensitive to proteasomal inhibition. Thus, the two CD99 variants seem to be more prone to misfolding. A formal induction of ER stress, however, was not observed. Cell biological effects of D92H, but not D92Y, were observed when this protein was overexpressed in HeLa cells. Here, cell migration significantly increased in an in vitro model when compared to CD99 WT. Thus D92H could destabilize binding of the cancer cell to the primary tumor or increase tumor cell extravasation and thereby favor metastasis. For other cell adhesion molecules, such as CECAM-1 or PECAM-1, similar involvement in cancer cell metastasis was described [27]. Of note, a previously described effect of CD99 on Src activation [24] or any changes for the two variants $\mathrm{D} 92 \mathrm{H}$ and D92Y could not be confirmed in this study. Instead, meprin $\beta$ significantly increased Src phosphorylation, independent of CD99, which might be an important pro-tumorigenic activity of this enzyme and warrants further analysis.

In summary, our results show that i) the ability of meprins to cleave the cancer-associated CD99 variants is not largely impaired although the cleavage site shifted, ii) both, D92H and D92Y seem to be partially misfolded and are more prone to proteasomal degradation than CD99 WT, and iii) D92H causes significantly higher cell migration compared to CD99 WT.

\section{MATERIALS AND METHODS}

\section{Cell culture and transient transfection}

HeLa, COLO 320, and U2-OS cells were grown in Dulbecco's Modified Eagle Medium (DMEM) supplemented with $10 \%$ fetal calf serum (FCS) at $37^{\circ} \mathrm{C}$ and $5 \% \mathrm{CO}_{2}$. For experiments involving treatment with recombinant meprin $\beta$, cells were cultured in serum-free medium during treatment to avoid protease inhibition by
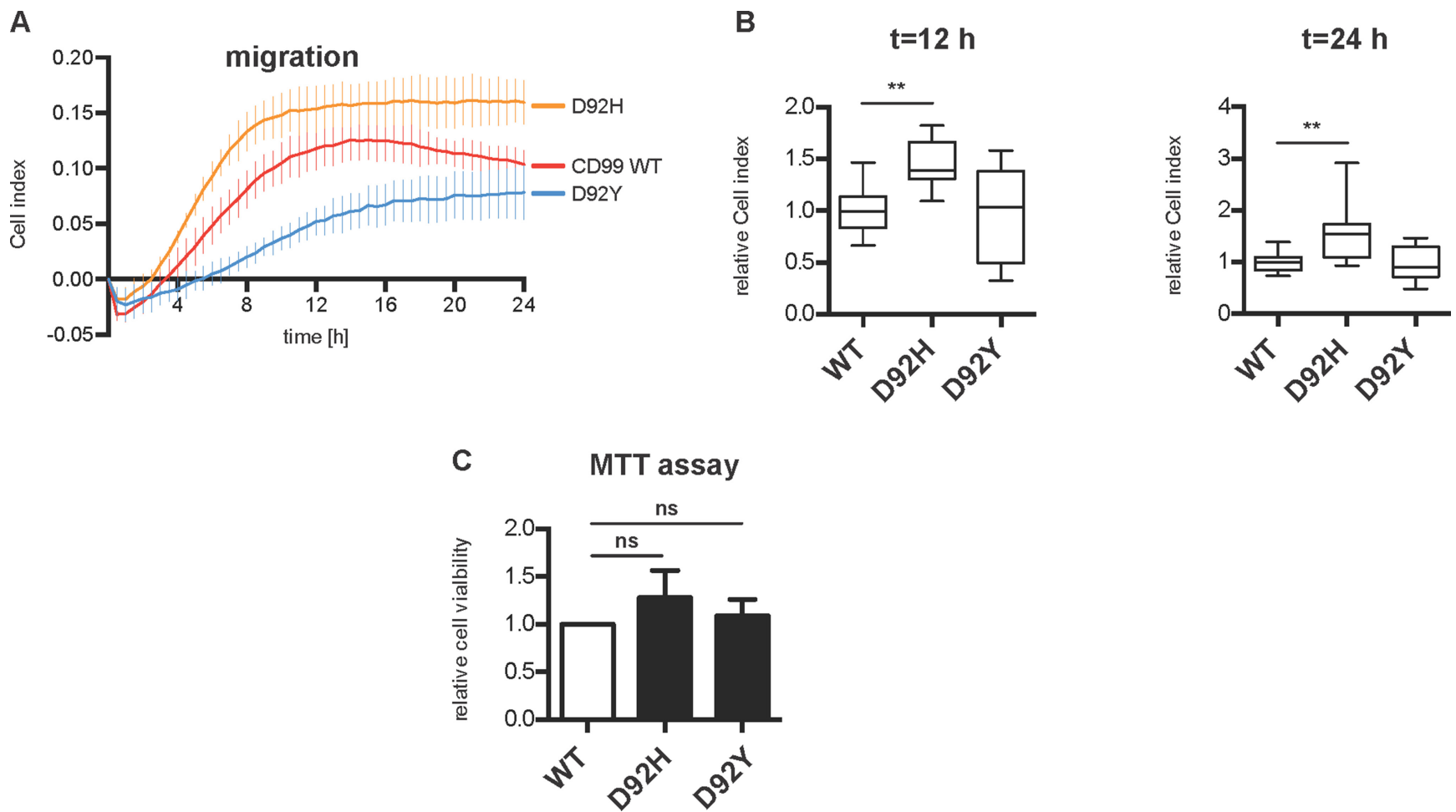

Figure 7: Overexpression of D92H variant increases cell migration in HeLa cells. (A) HeLa cells were transfected with CD99 WT, D92H, or D92Y. After solubilization, 40,000 cells were added to xCELLigence microelectrode-equipped transwell chambers in triplicates and allowed to migrate for $24 \mathrm{~h}$. Migration is monitored in real time as increase of impedance and is expressed as Cell index (CI), an arbitrary unit. (B) Quantification of CI values from (A) at time points $12 \mathrm{~h}$ and $24 \mathrm{~h}$. Data represent mean \pm SD of triplicates of four (CD99 WT and D92H) or three (D92Y) individual experiments (relative to CD99 WT). D92H-overexpressing cells show increased migration at both time points. ANOVA; $* * P<0.01$. (C) Cell proliferation was analyzed using an MTT assay. 
serum ingredients. Cells were transiently transfected at $60 \%$ confluency using polyethylenimine (PEI) and the following expression constructs: empty vector control (pcDNA3.1), human meprin $\beta$ (both pcDNA3.1, kindly provided by Erwin Sterchi), human CD99 WT (pCMV6 myc-/FLAGtagged, Origene, \#RC204056), and D92H and D92Y (self-mutated from hCD99 WT construct). For siRNA knockdown experiments U2-OS cells were transfected with Silencer Select CD99 siRNA or Silencer Select Negative Control siRNA (\#4392420 and \#4390843, respectively, Thermo Fisher Scientific) using the transfection reagent INTERFERRin (Polyplus transfection).

\section{Site-directed mutagenesis}

Human CD99 D92H and D92Y mutants were produced by site-directed mutagenesis with hCD99 WT myc-/FLAG-tagged construct serving as template DNA. The following primers were used: c. $274 \mathrm{G}>\mathrm{C}$ forward: $5^{\prime}$-cta gttcctccggtagcttttcacatgctgaccttgcggatggc-3', c.274G $>C$ reverse: 5'-gccatccgcaaggtcagcatgtgaaaagctaccggaggaac tag-3'; c274G $>$ T forward: 5'-ctagttcctccggtagcttttcatat gctgaccttgcggatggc-3'; c274G $>$ T reverse: 5'-gccatccgcaag gtcagcatatgaaaagctaccggaggaactag- $3^{\prime}$. Primers were phosphorylated, then added to template DNA and DNA was amplified by Phusion Taq DNA Polymerase (ThermoFisher). Methylated template DNA was then digested by DpnI enzyme and the amplified DNA was ligated. Introduction of both point mutations was confirmed by DNA sequencing (GATC Biotech).

\section{Cell lysates, SDS-PAGE, and western blot}

Cells were washed once with PBS, harvested using a sterile cell scraper, and centrifuged at $500 \mathrm{~g}$ for $10 \mathrm{~min}$ at $4^{\circ} \mathrm{C}$. The cell pellet was resuspended in lysis buffer (1 mM EGTA, 5 mM TRIS, $250 \mathrm{mM}$ saccharose, 1\% Triton $\mathrm{X}-100$, complete protease inhibitor (Roche), $\mathrm{pH}$ 7.4) and placed on ice for $30 \mathrm{~min}$. For phosphoproteins a different lysis buffer was used: $137 \mathrm{mM} \mathrm{NaCl}, 20 \mathrm{mM}$ TRIS, $1 \mathrm{mM}$ $\mathrm{Na}_{3} \mathrm{VO}_{4}, 1 \%$ NP-40, cOmplete proteinase inhibitor cocktail, PhosSTOP phosphatase inhibitor (both Roche), $\mathrm{pH}$ 8.0. Cell debris was removed by centrifugation at 13, $200 \mathrm{rpm}$ for $15 \mathrm{~min}$ at $4^{\circ} \mathrm{C}$ and supernatant was removed. The protein concentration was determined using a BCA protein assay kit (ThermoFisher) and equal amounts of protein were mixed with $5 \mathrm{X}$ reducing sample buffer and denatured at $95^{\circ} \mathrm{C}$ for $10 \mathrm{~min}$. Protein extracts were separated on $10 \%$ or $12 \%$ SDS-PAGE (130 V, $90 \mathrm{~min})$ and afterwards transferred onto nitrocellulose membranes using tank blot procedure ( $800 \mathrm{~mA}, 2 \mathrm{~h}$ ). Membranes were blocked in 5\% milk in TBS-T or 5\% BSA in TBS-T for phosphoprotein analysis for $1 \mathrm{~h}$ at room temperature and subsequently incubated with primary antibody in blocking solution at $4^{\circ} \mathrm{C}$ over night. The following primary antibodies were used: monoclonal anti myc (9B11, Cell Signaling, \#2276), polyclonal anti meprin $\beta$ (both selfmade, Pineda AntibodyService), monoclonal anti polyubiquitinylated proteins (FK1, Enzo, \#BML-PW8805), monoclonal anti Grp78 (C50B12, Cell Signaling, \#3177), monoclonal anti p-EIF2 $\alpha$ Ser51 (D9G8, Cell Signaling, \#3398), polyclonal anti Grp94 (Cell Signaling, \#2104), polyclonal anti Src (Cell Signaling, \#2108), polyclonal anti p-Src Tyr416 (Cell Signaling, \#2101), polyclonal anti PKA (Cell Signaling, \#4782), polyclonal anti p-PKA Thr197 (Cell Signaling, \#4781), polyclonal anti transferrin receptor (abcam, \#ab84036) polyclonal anti actin (Sigma, \#A2066), monoclonal anti GAPDH (14C10, Cell Signaling, \#2118). After washing with TBS-T, membranes were incubated with horseradish peroxidase-conjugated secondary antibody for $1 \mathrm{~h}$ at room temperature. Membranes were then washed again and proteins were detected using the SuperSignal West Femto Maximum Sensitivity Substrate (ThermoFisher) on a LAS3000 mini (Fujifilm) imaging system.

\section{Cell surface protein biotinylation}

Transfected cells were cooled down to $4{ }^{\circ} \mathrm{C}$ and washed with PBS-CM $\left(0.1 \mathrm{mM} \mathrm{CaCl}_{2}\right.$ and $1 \mathrm{mM} \mathrm{MgCl}_{2}$ in PBS). Biotin solution (1 mg/ml EZ-Link Sulfo-NHS-SSBiotin (ThermoFisher) in PBS-CM) was added for $30 \mathrm{~min}$ at $4^{\circ} \mathrm{C}$. Afterwards, cells were incubated with quenching buffer (50 mM TRIS, pH 8 in PBS-CM) for 10 min at $4^{\circ} \mathrm{C}$ and washed three times with PBS-CM. Cells were then harvested in PBS-CM and lysed (50 mM TRIS, $150 \mathrm{mM}$ $\mathrm{NaCl}, 1 \%$ Triton $\mathrm{X}-100,0.1 \%$ SDS, cOmplete protease inhibitor (Roche), $\mathrm{pH}$ 7.4). The total protein amount was determined using a BCA protein assay kit (ThermoFisher) and sufficient amount of lysate was taken for control Western blot analysis. The remaining lysate was incubated with washed High Capacity Streptavidin Agarose (ThermoFisher) for $1 \mathrm{~h}$ at $4^{\circ} \mathrm{C}$ to pull down biotinylated cell surface proteins. The agarose beads were washed three times with lysis buffer. Then, $80 \mu 1 \mathrm{X}$ reducing sample buffer was added and samples were heated for $30 \mathrm{~min}$ at $60^{\circ} \mathrm{C}$ to separate precipitated proteins from agarose beads. Whole lysates and precipitated proteins were then analyzed by Western blot.

\section{Recombinant proteins}

Recombinant meprin $\beta$ was expressed in insect cells using the Bac-to-Bac Baculovirus Expression System (ThermoFisher) and purified as described previously [28]. For cleavage assays, cells were washed twice with PBS and recombinant meprin $\beta$ was added in DMEM without FCS to circumvent protease inhibition by serum ingredients. For inhibition studies meprin $\beta$ was preincubated with the inhibitor actinonin in DMEM for $15 \mathrm{~min}$ at room temperature prior to application to the cells. 


\section{Peptide cleavage assays and HPLC analysis}

Peptide cleavage assays were performed as described before [9]. In short, synthetic peptides were obtained from Genosphere Biotechnologies and analyzed by reversed-phase high-performance liquid chromatography (RP-HPLC). The peptide solution $(500 \mu \mathrm{M})$ was either analyzed alone or after preceding incubation with recombinant meprin $\beta(15 \mathrm{nM})$ at room temperature. The digestion was stopped after each timepoint by addition of $0.1 \%$ trifluoroacetic acid. Collection of eluting fractions corresponding to chromatogram peaks was performed for subsequent mass spectrometry-assisted peptide analysis.

\section{Identification of cleavage sites from HPLC fractions: MALDI mass spectrometry}

A volume of $250 \mu \mathrm{l}$ from each LC-fraction was dried via vacuum centrifugation to concentrate the sample. The dried samples were reconstituted in $25 \mu 1$ of $3 \% \mathrm{ACN}$, in $0.1 \%$ TFA and $1 \mu \mathrm{l}$ of the sample was then spotted onto a MALDI target in duplicate and left to air-dry. MALDI matrix ( $3 \mathrm{mg} / \mathrm{ml}$ of alpha-cyano-4-hydroxycinnamic acid) in $70 \% \mathrm{ACN}, 0.1 \%$ TFA was then applied to the dried spots. MALDI MS/MS analysis was performed using an AB Sciex 5800 MALDI TOF/TOF mass spectrometer (ABSciex, Darmstadt, Germany). Measurement conditions were: reflectron positive ion mode; 2,000 laser shots per spot were acquired for MS spectra and a one point recalibration was performed using matrix peak at $\mathrm{m} / \mathrm{z}$ 877.034. For MS/MS experiments, 2,500 shots were averaged with a pulse rate of $1,000 \mathrm{~Hz}$. Precursor ions were separated by timed ion selection with 300 resolution window (FHWM). Peptides were fragmented either with post-source decay (PSD) or collision induced dissociation (CID) with deceleration to an energy of $1 \mathrm{kV}$. For CID experiments, ambient air was used as collision gas with medium pressure of 10-6 torr. Fragmentation spectra were analyzed with the "Ion fragmentation calculator" tool embedded in the Data explorer software 4.10 (AB Sciex) and manually inspected. Theoretical peptide masses and peptide mass deviations were calculated using Mmass (version 2.4).

\section{Identification of cleavage sites from cell lysates by SDS-PAGE, reductive dimethylationin-gel digestion and LC-MS/MS}

CD99 C-term was immunoprecipitated from HeLa cell lysates transfected with myc/FLAG-tagged CD99 and untagged meprin $\beta$ using an anti-FLAG antibody. The precipitate was separated by SDS-PAGE (12\% gel) and stained by Coomassie. Bands, (Supplementary Figure 4A) according to signals detected in a control Western blot (Supplementary Figure 4B), were excised using a scalpel. Reductive dimethylation and in-gel digestion was performed as reported previously with minor modifications [16], i.e., digestion was carried out with $50 \mathrm{ng}$ of chymotrypsin and $25 \mathrm{ng}$ trypsin overnight in $10 \mathrm{mM}$ HEPES buffer $\left(2 \mathrm{mM} \mathrm{CaCl}_{2}, \mathrm{pH} 7.5\right)$ at $37^{\circ} \mathrm{C}$.

LC-MS analyses were performed on an UltiMate 3000 RSL Nano/Cap System (Thermo, Bremen, Germany) coupled online to an OrbitrapQ Exactive mass spectrometer (Thermo). LC running conditions have been reported previously [29]. MS scans were acquired in the mass range of 300 to $2,000 \mathrm{~m} / \mathrm{z}$ at a resolution of 70,000 . The ten most intense signals were subjected to HCD (higher collisional energy dissociation) using a dynamic exclusion of $15 \mathrm{~s}$. MS/MS parameters: minimum signal intensity: 1000 , isolation width: $3.0 \mathrm{Da}$, charge state: $\geq 2$, HCD resolution: 15,000, Normalized collision energy of 25. Lock mass (445.120025) was used for data acquired in MS mode. HCD spectra were searched using Proteome Discoverer 1.4 (1.4.0.288, Thermo Fisher Scientific) with the Sequest-HT search algorithm against the reviewed and canonical human database with contaminants (ftp:// ftp.thegpm.org/fasta/cRAP/) and different mutants of CD99 appended to the database (20,319 sequences). The following database search settings were used: MS tolerance; $\pm 10 \mathrm{ppm}$, MS2 Tolerance; $0.02 \mathrm{Da}$, enzyme specificity; none, fixed modification at lysine (dimethylation) and cysteine (carbamidomethylation) residues. Modification at the peptide N-terminus (dimethylation) was set as a variable modification.

\section{Immunocytochemistry}

HeLa cells were analyzed by immunofluorescence as described before [9]. In short, cells were seeded onto coverslips, transfected, and fixed with paraformaldehyde. After blocking and permeabilization, primary antibodies (anti myc, 1:1000; anti meprin $\beta, 1: 500$ ) were added over night at $4{ }^{\circ} \mathrm{C}$. Secondary antibodies (Alexa Fluor 488 and 594) were applied for $1 \mathrm{~h}$ at room temperature before mounting the coverslips on glass slides together with DAPI for nuclear staining. Images were then acquired with a confocal laser scanning microscope (FV1000, Olympus).

\section{Flow cytometry}

CD99 surface expression was monitored by flow cytometry. Cells were detached using Accutase (SigmaAldrich), pelleted, resuspended in FACS buffer (1\% BSA in PBS) and $10^{6}$ cells were incubated with phycoerythrin (PE)-labeled anti human CD99 antibody (BioLegend, \#318008) or PE-labeled IgG2a isotype control antibody (BioLegend, \#400214) for $30 \mathrm{~min}$ on ice. Cells were then pelleted, washed twice, and resuspended in FACS buffer. Flow cytometric analysis was carried out on a Becton Dickinson FACS Canto system. Data analysis was performed using FlowJo software, V10.1. 


\section{RNA isolation and RT-PCR}

Total RNA from HeLa cells was extracted using the NucleoSpin ${ }^{\circledR}$ RNA isolation kit (MACHEREY-NAGEL) according to the manufacturer's instructions. Amount and quality of extracted RNA was determined with Nanodrop (Thermo Fisher Scientific) by the absorbance at $260 \mathrm{~nm}$ and by the ratio of $280 / 260 \mathrm{~nm}$. Total mRNA was reverse transcribed using RevertAid RT Reverse Transcription Kit (Thermo Fisher Scientific) according to the manufacturer's instructions. The PCR reaction was prepared with the DreamTag DNA Polymerase kit (Thermo Fisher Scientific) according to the manufacturer's instructions and the reaction products were separated and visualised on a $2.5 \%$ agarose gel. The following primers were used: hXBPl 5'-TTACGAGAGAAAACTCATGGCC-3' and 5'-GGGTCCAAGTTGTCCAGAATGC-3'.

\section{Migration assay}

HeLa cells were transfected with different CD99 constructs, detached using a cell scraper, counted, and resuspended in DMEM, 1\% FCS. The real-time migration assay was performed using the xCELLigence RTCA DP analyzer (ACEA Biosciences). A CIM-Plate 16 was assembled and equilibrated with DMEM, 1\% FCS for $1 \mathrm{~h}$. Then 40,000 cells were added and allowed to migrate through the microporous membrane for $24 \mathrm{~h}$. Results are expressed as cell index $(\mathrm{CI})$, a relative unit reflecting the electrical impedance measurement at the bottom of the microporous membrane.

\section{Cell viability assay}

HeLa cells were transfected with human CD99 WT, D92H, D92Y or empty control vector. Cells were seeded in a 96 well plate at a density of 50,000 cells per well. Next day, 96 well plate was centrifuged to pellet the cells, medium was removed and exchanged with $100 \mu \mathrm{l}$ fresh culture medium. To each well $10 \mu \mathrm{l}$ of a $12 \mathrm{mM}$ MTT (Sigma) solution were added and incubated for $2.5 \mathrm{~h}$ at $37^{\circ} \mathrm{C}$. Upon addition of $100 \mu \mathrm{l}$ SDS-HCl solution (10\% SDS in $0.01 \mathrm{M}$ $\mathrm{HCl})$ to each well and mixture using a pipette, microplate was again incubated for $2.5 \mathrm{~h}$ at $37^{\circ} \mathrm{C}$. Afterwards, each sample was mixed again and the absorbance was detected at $570 \mathrm{~nm}$. Relative cell viability was calculated by setting empty vector transfected cells to $100 \%$.

\section{Mice}

The generation of $M e p 1 b^{-/}$mice has been described previously [30]. Mice were kept under specific pathogen free conditions in isolated ventilated cages, on a $12 \mathrm{~h}$ light-dark cycle with food and water ad libitum. Our investigations were carried out in accordance to the Guide for the Care and Use of Laboratory Animals of the German Animal Welfare Act on protection of animals. All animal protocols were approved by the Central Animal Facility of the University of Kiel and the relevant German authorities.

\section{Air-pouch mouse model}

The air pouch model was performed as described previously [31, 32]. Briefly, subcutaneous injection of $6 \mathrm{ml}$ sterile air into the back of 9-11 week old mice lead to dorsal pouches, which were re-injected with $4 \mathrm{ml}$ of sterile air 3 days later. On day 6,1 $\mathrm{ml}$ of $1 \%$ carrageenan (SigmaAldrich) in sterile PBS was injected into the pouches to induce an inflammatory response. $24 \mathrm{~h}$ after induction of inflammation blood was collected submandibular, mice were killed by cervical dislocation and the pouches were washed with $3 \mathrm{ml}$ of $2 \mathrm{mM}$ EDTA/PBS. Lavage fluid was immediately stored on ice and cells counted using Cellometer automated cell counter. Aliquots of 500000 pouch cells or blood diluted in $40 \mathrm{mM}$ EDTA/PBS were used for FACS analysis. After blocking Fc-receptors with mouse Fc block CD16/32 mAb (Biolegend) cells were stained with fluorescence-coupled mAbs against CD45 (30-F11), CD115 (AFS98), CD11b (M1/70), Ly6G (1A8), Ly6C (HK1.4) (Biolegend) and CD99 (\#FAB3905P) or respective isotype control (\#IC108P) both purchased from R\&D Systems. Cells were fixed with RBC Lysis/Fixation Solution (Biolegend) and analysed by flow cytometry (FACS Canto II, BD). Data were analysed using FlowJo software (V 10.1).

\section{Statistical analysis}

All statistical analysis was performed using Graph Pad Prism 6 software for Student's t test or one way ANOVA followed by a Tukey multiple comparison post hoc test. Values are expressed as mean $\pm \mathrm{SD}$. The null hypothesis was rejected at $\mathrm{P}<0.05(* P<0.05$, $* * P<0.01, * * * P<0.001)$.

\section{Abbreviations}

TEM: transendothelial migration; ECM: extracellular matrix; UPR: unfolded protein response; HCR: highly conserved region; CTF: C-terminal fragment

\section{Author contributions}

TB, NS, FP, JP, PA, TK, and OH performed experiments. BR, MJ, PR, SS, AT, and SRJ provided materials and/or technical assistance. CBP supervised the study. TB and CBP wrote the paper.

\section{ACKNOWLEDGMENTS}

We thank Inez Götting for excellent assistance in animal care. We thank Dr. Michelle Rothaug for proofreading. 


\section{CONFLICTS OF INTEREST}

The authors declare that they have no conflicts of interest.

\section{FUNDING}

This work was supported by the Deutsche Forschungsgemeinschaft (DFG) SFB877 "Proteolysis as a Regulatory Event in Pathophysiology" (projects A1, A9, B9 and Z2), and grant BE4086/5-1 (to CBP).

\section{REFERENCES}

1. Dworzak MN, Fritsch G, Buchinger P, Fleischer C, Printz D, Zellner A, Schöllhammer A, Steiner G, Ambros PF, Gadner H. Flow cytometric assessment of human MIC2 expression in bone marrow, thymus, and peripheral blood. Blood. 1994; 83:415-25.

2. Schenkel AR, Mamdouh Z, Chen X, Liebman RM, Muller WA. CD99 plays a major role in the migration of monocytes through endothelial junctions. Nat Immunol. 2002; 3:143-50.

3. Lou O, Alcaide P, Luscinskas FW, Muller WA. CD99 is a key mediator of the transendothelial migration of neutrophils. J Immunol. 2007; 178:1136-43. https://doi. org/10.4049/jimmunol.178.2.1136.

4. Winger RC, Harp CT, Chiang M-Y, Sullivan DP, Watson RL, Weber EW, Podojil JR, Miller SD, Muller WA. Cutting Edge: CD99 Is a Novel Therapeutic Target for Control of T Cell-Mediated Central Nervous System Autoimmune Disease. J Immunol. 2016; 196: 1501634-1448. https://doi. org/10.4049/jimmunol.1501634.

5. Ambros IM, Ambros PF, Strehl S, Kovar H, Gadner H, Salzer-Kuntschik M. MIC2 is a specific marker for Ewing's sarcoma and peripheral primitive neuroectodermal tumors. Evidence for a common histogenesis of Ewing's sarcoma and peripheral primitive neuroectodermal tumors from MIC2 expression and specific chromosome aberration. Cancer. 1991; 67:1886-93.

6. Fellinger EJ, Garin-Chesa P, Triche TJ, Huvos AG, Rettig WJ. Immunohistochemical analysis of Ewing's sarcoma cell surface antigen p30/32MIC2. Am J Pathol. 1991; 139:317-25.

7. Manara MC, Bernard G, Lollini PL, Nanni P, Zuntini M, Landuzzi L, Benini S, Lattanzi G, Sciandra M, Serra M, Colombo MP, Bernard A, Picci P, Scotlandi K. CD99 acts as an oncosuppressor in osteosarcoma. Mol Biol Cell. 2006; $17: 1910-21$.

8. Jefferson T, Auf dem Keller U, Bellac C, Metz VV, Broder C, Hedrich J, Ohler A, Maier W, Magdolen V, Sterchi E, Bond JS, Jayakumar A, Traupe H, et al. The substrate degradome of meprin metalloproteases reveals an unexpected proteolytic link between meprin $\beta$ and ADAM10. Cell Mol Life Sci. 2013; 70:309-33.
9. Bedau T, Peters F, Prox J, Arnold P, Schmidt F, Finkernagel M, Köllmann S, Wichert R, Otte A, Ohler A, Stirnberg M, Lucius R, Koudelka T, et al. Ectodomain shedding of CD99 within highly conserved regions is mediated by the metalloprotease meprin $\beta$ and promotes transendothelial cell migration. FASEB J. 2017; 31:1226-37.

10. Becker-Pauly C, Barré O, Schilling O, Auf dem Keller U, Ohler A, Broder C, Schütte A, Kappelhoff R, Stöcker W, Overall CM. Proteomic analyses reveal an acidic prime side specificity for the astacin metalloprotease family reflected by physiological substrates. Mol Cell Proteomics. 2011; 10: M111.009233-M111. https://doi.org/10.1074/mcp. M111.009233.

11. Broder C, Becker-Pauly C. The metalloproteases meprin $\alpha$ and meprin $\beta$ : unique enzymes in inflammation, neurodegeneration, cancer and fibrosis. Biochem J. 2013; 450:253-64.

12. Jefferson $\mathrm{T}$, Čaušević M, auf dem Keller U, Schilling O, Isbert S, Geyer R, Maier W, Tschickardt S, Jumpertz T, Weggen S, Bond JS, Overall CM, Pietrzik CU, BeckerPauly C. Metalloprotease meprin beta generates nontoxic $\mathrm{N}$-terminal amyloid precursor protein fragments in vivo. $\mathrm{J}$ Biol Chem. 2011; 286:27741-50.

13. Bien J, Jefferson T, Causević M, Jumpertz T, Munter L, Multhaup G, Weggen S, Becker-Pauly C, Pietrzik CU. The metalloprotease meprin $\beta$ generates amino terminaltruncated amyloid $\beta$ peptide species. J Biol Chem. 2012; 287:33304-13.

14. Schönherr C, Bien J, Isbert S, Wichert R, Prox J, Altmeppen H, Kumar S, Walter J, Lichtenthaler SF, Weggen S, Glatzel M, Becker-Pauly C, Pietrzik CU. Generation of aggregation prone $\mathrm{N}$-terminally truncated amyloid $\beta$ peptides by meprin $\beta$ depends on the sequence specificity at the cleavage site. Mol Neurodegener. 2016; 11:19.

15. Schütte A, Ermund A, Becker-Pauly C, Johansson ME, Rodriguez-Pineiro AM, Bäckhed F, Müller S, Lottaz D, Bond JS, Hansson GC. Microbial-induced meprin $\beta$ cleavage in MUC2 mucin and a functional CFTR channel are required to release anchored small intestinal mucus. Proc Natl Acad Sci USA. 2014; 111:12396-401.

16. Broder C, Arnold P, Vadon-Le Goff S, Konerding MA, Bahr K, Müller S, Overall CM, Bond JS, Koudelka T, Tholey A, Hulmes DJ, Moali C, Becker-Pauly C. Metalloproteases meprin $\alpha$ and meprin $\beta$ are $C$ - and $\mathrm{N}$-procollagen proteinases important for collagen assembly and tensile strength. Proc Natl Acad Sci USA. 2013; 110:14219-24.

17. Carr JC, Sherman SK, Wang D, Dahdaleh FS, Bellizzi AM, O'Dorisio MS, O'Dorisio TM, Howe JR. Overexpression of membrane proteins in primary and metastatic gastrointestinal neuroendocrine tumors. Ann Surg Oncol. 2013; 20:S739-46.

18. Maitra A, Hansel DE, Argani P, Ashfaq R, Rahman A, Naji A, Deng S, Geradts J, Hawthorne L, House MG, Yeo CJ. Global expression analysis of well-differentiated 
pancreatic endocrine neoplasms using oligonucleotide microarrays. Clin Cancer Res. 2003; 9:5988-95.

19. Vestweber D. How leukocytes cross the vascular endothelium. Nat Rev Immunol. 2015; 15:692-704.

20. Park SH, Shin YK, Suh YH, Park WS, Ban YL, Choi HS, Park HJ, Jung KC. Rapid divergency of rodent CD99 orthologs: implications for the evolution of the pseudoautosomal region. Gene. 2005; 353:177-88.

21. Suh YH, Shin YK, Kook MC, Oh KI, Park WS, Kim SH, Lee IS, Park HJ, Huh TL, Park SH. Cloning, genomic organization, alternative transcripts and expression analysis of CD99L2, a novel paralog of human CD99, and identification of evolutionary conserved motifs. Gene. 2003; 307:63-76.

22. Wu TJ, Shamsaddini A, Pan Y, Smith K, Crichton DJ, Simonyan V, Mazumder R. A framework for organizing cancer-related variations from existing databases, publications and NGS data using a High-performance Integrated Virtual Environment (HIVE). Database (Oxford). 2014; 2014:bau022. https://doi.org/10.1093/database/ bau022.

23. Kruse MN, Becker C, Lottaz D, Köhler D, Yiallouros I, Krell HW, Sterchi EE, Stöcker W. Human meprin alpha and beta homo-oligomers: cleavage of basement membrane proteins and sensitivity to metalloprotease inhibitors. Biochem J. 2004; 378:383-89.

24. Scotlandi K, Zuntini M, Manara MC, Sciandra M, Rocchi A, Benini S, Nicoletti G, Bernard G, Nanni P, Lollini PL, Bernard A, Picci P. CD99 isoforms dictate opposite functions in tumour malignancy and metastases by activating or repressing c-Src kinase activity. Oncogene. 2007; 26:6604-18.

25. Watson RL, Buck J, Levin LR, Winger RC, Wang J, Arase H, Muller WA. Endothelial CD99 signals through soluble adenylyl cyclase and PKA to regulate leukocyte transendothelial migration. J Exp Med. 2015; 212:1021-41.

26. Becker A, Thakur BK, Weiss JM, Kim HS, Peinado H, Lyden D. Extracellular Vesicles in Cancer: Cell-to-Cell Mediators of Metastasis. Cancer Cell. 2016; 30:836-48.

27. Paschos KA, Canovas D, Bird NC. The role of cell adhesion molecules in the progression of colorectal cancer and the development of liver metastasis. Cell Signal. 2009; 21:665-74.

28. Becker C, Kruse MN, Slotty KA, Köhler D, Harris JR, Rösmann S, Sterchi EE, Stöcker W. Differences in the activation mechanism between the $\alpha$ and $\beta$ subunits of human meprin. Biol Chem. 2003; 384:825-31.

29. Somasundaram P, Koudelka T, Linke D, Tholey A. C-Terminal Charge-Reversal Derivatization and Parallel Use of Multiple Proteases Facilitates Identification of Protein C-Termini by C-Terminomics. J Proteome Res. 2016; 15:1369-78.

30. Norman LP, Jiang W, Han X, Saunders TL, Bond JS. Targeted disruption of the meprin beta gene in mice leads to underrepresentation of knockout mice and changes in renal gene expression profiles. Mol Cell Biol. 2003; 23:1221-30.

31. Rabe B, Chalaris A, May U, Waetzig GH, Seegert D, Williams AS, Jones SA, Rose-John S, Scheller J. Transgenic blockade of interleukin 6 transsignaling abrogates inflammation. Blood. 2008; 111:1021-28.

32. Schumacher N, Schmidt S, Schwarz J, Dohr D, Lokau J, Scheller J, Garbers C, Chalaris A, Rose-John S, Rabe B. Circulating Soluble IL-6R but Not ADAM17 Activation Drives Mononuclear Cell Migration in Tissue Inflammation. J Immunol. 2016; 197:3705-15. 